\title{
OXYTOCIN (OT) AND ARGININE-VASOPRESSIN (AVP) ACT ON OT RECEPTORS AND NOT AVP V1A RECEPTORS TO ENHANCE SOCIAL RECOGNITION IN ADULT SYRIAN HAMSTERS (MESOCRICETUS AURATUS)
}

Zhimin Song, Tony E. Larkin, Maureen O’ Malley, H. Elliott Albers

Neuroscience Institute, Center for Behavioral Neuroscience, Georgia State University, Atlanta, GA USA

Manuscript correspondence, proofs, and reprint requests may be addressed to:

H. Elliott Albers, Ph.D.

Neuroscience Institute

Georgia State University

P.O. Box 5030

Atlanta, GA USA 30302-5030

Telephone: (404)413-5346

Email: biohea@gsu.edu

Running title: Oxytocin and Vasopressin enhance social recognition by acting on oxytocin receptors 
Oxytocin (OT) and arginine-vasopressin (AVP) act on OT receptors and not AVP V1a receptors to enhance social recognition in adult Syrian hamsters (Mesocricetus auratus)

Authors: Zhimin Song, Tony E. Larkin, Maureen O’ Malley, H. Elliott Albers

Abstract

Social recognition is a fundamental requirement for all forms of social relationships. A majority of studies investigating the neural mechanisms underlying social recognition in rodents have investigated relatively neutral social stimuli such as juveniles or ovariectomized females over short time intervals (e.g., $2 \mathrm{hrs}$ ). The present study developed a new testing model to study social recognition among adult males using a potent social stimulus. Flank gland odors are used extensively in social communication in Syrian hamsters and convey important information such as dominance status. We found that the recognition of flank gland odors after a 3 min exposure lasted for at least $24 \mathrm{hrs,} \mathrm{substantially} \mathrm{longer} \mathrm{than} \mathrm{the}$ recognition of other social cues in rats and mice. Intracerebroventricular injections of OT and AVP prolonged the recognition of flank gland odor for up to $48 \mathrm{hrs}$. Selective OTR but not V1aR agonists, mimicked these enhancing effects of OT and AVP. Similarly, selective OTR but not V1aR antagonists blocked recognition of the odors after $20 \mathrm{~min}$. In contrast, the recognition of non-social stimuli was not blocked by either the OTR or the V1aR antagonists. Our findings suggest both OT and AVP enhance social recognition via acting on OTRs and not V1aRs and that the recognition enhancing effects of OT and AVP are limited to social stimuli.

Keywords: social behavior; nonapeptides; neuropeptides; neurohypophyseal hormones; social communication; flank marking; chemosensory, olfaction; odor recognition; memory

Introduction 
The ability to recognize one individual from another of the same species is a fundamental requirement for nearly all forms of social relationships including pair bonding, maternal behavior and dominance (Petrulis 2009, Gabor, Phan et al. 2012). Social recognition is expressed in many different levels of complexity from the relatively simple ability to discriminate between familiar and unfamiliar social cues to the true recognition of specific individuals as well as recognition of kin (Johnston and Bullock 2001, Choleris, Clipperton-Allen et al. 2009). There is a wealth of data demonstrating that species such as mice, rats, hamsters, and gerbils can display basic levels of social discrimination in the laboratory (Halpin 1976, Johnston 1993, Choleris, Clipperton-Allen et al. 2009, Gabor, Phan et al. 2012).

To date, a majority of social recognition studies have focused on the ability of an adult rodent to recognize a juvenile or an ovariectomized female of the same species (Le Moal, Dantzer et al. 1987, Ferguson, Young et al. 2000, Ferguson, Aldag et al. 2001, Winslow and Insel 2004, Veenema, Bredewold et al. 2012). This approach was taken to investigate the social recognition of a relatively "neutral" social stimulus. Rats and mice fail to recognize a juvenile or an ovariectomized female within $2 \sim 3$ hrs after an initial encounter in most behavioral tests (Ferguson, Aldag et al. 2001, Winslow and Insel 2004, Veenema, Bredewold et al. 2012), perhaps because of the neutral nature of the social stimulus. In the present study we investigated the duration of social recognition in adult male Syrian hamsters (Mesocricetus auratus) using odors obtained from flank glands as the social cue. Flank gland odor is a powerful social cue that serves to communicate a variety of different types of social information in hamsters including dominance status (Johnston and Lee 1976, Ferris, Albers et al. 1984, Ferris, Axelson et al. 1987). As such, investigating the recognition of flank gland odors in adult males provides a social recognition test with a high degree of relevance and validity for understanding of social memory.

The nonapeptides oxytocin (OT) and arginine vasopressin (AVP) are both involved in the regulation of social recognition in many species including mice and rats (Albers 2012, Gabor, Phan et al. 2012, Caldwell and Albers 2015). For instance, mice lacking the OT gene have severe impairments in their ability to recognize other individuals (Ferguson, Young et al. 2000, Winslow and Insel 2004) and 
centrally or peripherally injected AVP facilitates social memory in rats (Le Moal, Dantzer et al. 1987, Veenema, Bredewold et al. 2012). OT and AVP have a high degree of similarity in their structure and in the structure of their canonical receptors (Gimpl and Fahrenholz 2001, Maybauer, Maybauer et al. 2008, Manning, Misicka et al. 2012, Song, McCann et al. 2014). Recently it has been demonstrated that both OT and AVP can produce functionally significant responses by activating AVP V1a receptors (V1aRs) (Schorscher-Petcu, Sotocinal et al. 2010, Sala, Braida et al. 2011, Ramos, Hicks et al. 2013, Qiu, Qiu et al. 2014, Albers 2015). For example, both OT and AVP can induce communicative behavior in hamsters when injected into the lateral ventricle and do so by activating V1a receptors and not OT receptors (OTRs) (Song, McCann et al. 2014).

In the present study, we demonstrate that adult male hamsters can recognize social odors from other adult male hamsters for at least $24 \mathrm{hrs}$ and that centrally administered OT and AVP significantly enhance the duration of social recognition in this species. Further, we demonstrate for the first time that OT and AVP can produce behavioral effects by acting on OTRs and not V1aRs using highly selective OT and AVP1a receptor agonists and antagonists.

Materials and Methods

Animals

Adult male Syrian hamsters (Charles River Laboratories Inc., Wilmington, MA, USA), 2-5 months old, weighing between 110-150g were used in all experiments. All experimental hamsters were individually housed in polycarbonate cages $(23 \times 43 \times 20 \mathrm{~cm})$ for 14 days prior to experimental use. Scent donor hamsters had been housed in groups (4 per cage) when used as non-aggressive intruders in a previous experiment. These hamsters were then housed singly for at least 7 days prior to scent donation for the current experiment. Hamsters were kept on a 14:10 light/dark cycle with food and water ad libitum. All experimental procedures were in accordance with the National Institutes of Health 
Guidelines for the Use of Animals and were approved by the Georgia State University Animal Care and Use Committee.

Surgery, microinjections, and histology

Hamsters were deeply anesthetized via 5\% isoflurane in an induction chamber and maintained with $3.75 \%$ isoflurane throughout all surgical procedures. Each subject was implanted with a 4mm, 26gauge cannula guide aimed at the left lateral ventricle. The skull was leveled and the guide cannula was implanted using the stereotaxic coordinates: $+0.8 \mathrm{~mm}$ anterior to bregma, $-1.1 \mathrm{~mm}$ from the midline, and 2.2mm below dura. Hamsters were allowed one week to recover from surgery before behavioral testing.

Introcerebroventricular (ICV) injections were administered over the course of 1 min into the lateral ventricle using an infusion pump (Harvard Apparatus), a $5 \mu 1$ Hamilton syringe, and a 14mm, 32gauge needle. The volume of all microinjections was $1 \mu$ l. Post-injection, the needle was left in the cannula guide for an additional minute to allow drug diffusion into the ventricle. Hamsters were sacrificed by lethal injection of sodium pentobarbital after testing and were injected with ink to verify the injection sites.

Drugs

The following drugs were injected: $9 \mu \mathrm{M}$ OT (Bachem, CA, USA) and $9 \mu \mathrm{M}$ AVP (Fisher scientific, TX, USA); 27 $\mu \mathrm{M}$ [Thr4,Gly7]OT (TGOT, a highly selective OT receptor agonist, a gift of Dr. Maurice Manning); $0.23 \mu \mathrm{M}$ [Phe2]OVT (a highly selective V1a receptor agonist, a gift of Dr. Maurice Manning); 90 $\mu \mathrm{M}$ desGly-NH2-d(CH2)5[D-Tyr2,Thr4]OVT (a selective OTR antagonist, OTA, a gift of Dr. Maurice Manning) and $90 \mu \mathrm{M} d(\mathrm{CH} 2) 5[\mathrm{Tyr}(\mathrm{Me}) 2] \mathrm{AVP}$ (a selective V1aR antagonist known as Manning Compound, a gift of Dr. Maurice Manning). The concentration of OT and AVP administered was based on the concentrations used in previous studies that were found effective in altering other social behavior in hamsters and other studies on social recognition in rats (Dantzer, Koob et al. 1988, Engelmann and Landgraf 1994, Song, McCann et al. 2014). The concentrations of the OT and AVP 
agonists were based on their relative efficacies compared to those of OT and AVP in binding to OTR and V1aR in rats, respectively (Manning, Misicka et al. 2012). The concentration of both OTR and V1aR antagonists were based on the concentration established in previous studies that was found to block social behavior in hamsters and rats (Albers, Pollock et al. 1986, Ferris, Singer et al. 1988, Nephew and Bridges 2008). All control animals were given a $1 \mu$ injection of saline.

Behavioral Testing

\section{Recognition of social odors}

The goal of Experiment 1 was to determine how long hamsters can recognize a conspecific odor. Hamsters were placed in a cage $(23 \times 43 \times 20 \mathrm{~cm})$ with a glass microscope slide $(25 \mathrm{~mm} \times 75 \mathrm{~mm} \times 1 \mathrm{~mm})$ taped to a cage wall approximately $2 \mathrm{~cm}$ from the floor for $3 \mathrm{~min}$ (Trial 1 ); the slide was scented with a fresh flank gland odor, collected from another adult male conspecific within 15 min before testing. Odors were deposited on the slides by gently holding hamsters and rubbing the slides against the flank gland regions 20 times. After this initial exposure to the odor stimulus hamsters were given a second odor exposure 20 minutes $(\min )(n=9), 24$ hours $(h r)(n=9), 48 \mathrm{hr}(\mathrm{n}=7)$, or 7 days $(\mathrm{n}=7)$ later. This odor test consisted of placing the hamster in a cage with one slide taped to one cage wall and another slide taped to the opposite cage wall for 3 min (Trial 2). One slide was scented with fresh flank gland odor of the same conspecific from Trial 1 (familiar odor) and the other slide with fresh flank gland odor of a novel male conspecific (novel odor). The familiar and novel stimulus hamsters were counterbalanced and derived from two cohorts of animals that were different in age by 1-3 months. Testing took place in a room with red dim lights and within the first $3 \mathrm{hr}$ of the dark phase of the light-dark cycle. Time spent sniffing the odor was recorded and scored later by a trained experimenter blind to experimental conditions.

The data collected in Experiment 1 showed that hamsters can recognize a previously encountered flank gland odor from a novel flank gland odor for $20 \mathrm{~min}$ and $24 \mathrm{hr}$ but not for $48 \mathrm{hr}$ or 7 days after the 
initial encounter. The goal of Experiments $2 \& 3$ was to test whether OT, AVP and selective OTR and V1aR agonists were able to increase the duration of social recognition from $24 \mathrm{hr}$ to $48 \mathrm{hr}$. The protocol for Experiments $2 \& 3$ was the same as in Experiment 1 except hamsters were injected with either OT, AVP, a selective OTR agonist, a selective V1aR agonist, or saline into the ventricle immediately

following Trial 1. Briefly, hamsters were placed in a cage to allow for investigation of a conspecific odor for 3 min (Trial 1). In Experiment 2, hamsters were injected with OT $(n=8)$, AVP $(n=7)$, or saline $(n=$ 6) immediately following the initial odor exposure. In Experiment 3, hamsters were injected with the OTR agonist $(n=9)$, the V1aR agonist $(n=9)$, or saline $(n=3)$ immediately following the initial odor exposure. Forty-eight hours later, they were again placed in a cage to allow for investigation of an odor from the previously encountered conspecific (familiar odor) and an odor from a novel conspecific (novel odor) for $3 \min ($ Trial 2).

Experiment 4 determined whether OTR and V1aR antagonists injected into the ventricle could block social recognition 20min after an initial odor exposure. The protocol for Experiment 4 was the same as in Experiments $2 \& 3$ except the time between the first odor exposure and the odor test was $20 \mathrm{~min}$. The OTR $(\mathrm{n}=11), \mathrm{V} 1 \mathrm{aR}(\mathrm{n}=8)$ antagonists or saline $(\mathrm{n}=10)$ were injected before the initial odor exposure in order to allow time for the antagonists to act before the first odor exposure.

\section{Recognition for non-social stimulus}

The goal of Experiments 5\&6 was to examine whether the effects of OT and AVP were specific to social odors or whether these neuropeptides influenced the recognition of non-social odors as well. Lemon extract and a cocktail of lemon extract and vanilla extract were used as non-social odors in these experiments. The lemon and vanilla extracts were purchased at a grocery store and the cocktail was made of $90 \%$ of lemon and $10 \%$ of vanilla. Hamsters' initial preference for the lemon scent was determined after the lemon and the cocktail of lemon and vanilla were simultaneously presented to hamsters in a pilot experiment. In the experiments thereafter, the lemon scent was presented to hamsters for $3 \mathrm{~min}$ as the first odor. In the second odor exposure, both the lemon and the cocktail were simultaneously presented to 
hamsters for $3 \mathrm{~min}$ in Trial. The odors were presented to hamsters in a similar manner as in Experiments 1-4. Each odor (10ul) was pipetted onto the center of a microscope slide and then the slide was taped to a wall of the cage, approximately $2 \mathrm{~cm}$ above the floor. The slides of lemon and the cocktail were placed on opposite sides of the cage and their locations were counterbalanced. Experiment 5 examined how long hamsters could recognize a non-social odor after an initial exposure. The odor test occurred $20 \mathrm{~min}(\mathrm{n}=$ 6), $60 \mathrm{~min}(\mathrm{n}=6)$, and $24 \mathrm{hr}(\mathrm{n}=6)$ after the initial odor exposure. Because this initial experiment found that the lemon scent could be recognized for $20 \mathrm{~min}$ and $60 \mathrm{~min}$, but not $24 \mathrm{hr}$, the ability of the OTR and V1aR antagonists to block recognition was tested after 20 min. In Experiment 6, hamsters were randomly divided into 3 groups and were injected with 90uM OTR antagonist $(\mathrm{n}=12), 90 \mathrm{uM} \mathrm{V1aR}$ antagonist $(n=6)$, or saline $(n=9)$ immediately before the initial odor exposure. The odor test took place 20 min after the initial odor exposure.

\section{Analysis of the Duration of Odor Investigation}

Across all social recognition experiments, hamsters spent between 12.4 \pm 1.3 (Mean \pm SEM) sec and 18.6 $\pm 3.2 \mathrm{sec}$ in trial 1 , and between $8.8 \pm 1.3 \mathrm{sec}$ and $17.3 \pm 2.0 \mathrm{sec}$ on average in trial 2 . There was no significant differences in time spent sniffing the odor stimulus between trial 1 and trial 2 across all groups, suggesting drug treatments did not affect sniffing time in trial 2. In all non-social recognition tests, hamsters appeared to spend less time in investigating lemon and vanilla scents during testing. Each group of hamsters spent between $4.1 \pm 0.8 \mathrm{sec}$ and $9.3 \pm 0.8$ in trial 1 , and between $2.5 \pm 0.3 \mathrm{sec}$ and $10.4 \pm 1.6 \mathrm{sec}$ in trial 2.

Data analyses and statistics

SPSS V21 was used to analyze all the data. All data are presented as mean \pm standard error of the mean. In all experiments, percentage of time spent sniffing a specific odor over the total sniffing time was presented in order to reduce the variation among the hamsters in their overall sniffing levels. Pairedsample Student's $t$-test was used to detect differences in the percentages of time spent with a previously 
exposed odor/scent versus the percentage of time spent with a novel odor/scent. One-way ANOVA test was used to detect differences in the percentage of time spent with the novel odor versus the familiar odor among animals injected with saline and drugs of interest (difference ratio $=($ Time spent with the Novel Time spent with the Familiar) / (Time spent with the Novel + Time spent with the Familiar)). All post hoc comparisons were determined a priori; planned contrasts were performed following significant

differences found in ANOVA tests. To determine effect sizes, eta squared, $\eta^{2}$ for ANOVA and Cohen's $\mathrm{d}, d$, for pair-wise comparisons and $t$ tests were calculated. All tests were two tailed and differences were considered significant at $\mathrm{p} \leq 0.05$.

Results

Recognition of social odors

Experiment 1: How long do hamsters recognize a previously encountered social odor?

Hamsters were first exposed to a flank gland odor for $3 \mathrm{~min}$ and then tested $20 \mathrm{~min}, 24 \mathrm{hr}, 48 \mathrm{hr}$, or 7 days later, in a social discrimination test with the same flank gland odor and a novel flank gland odor. Hamsters that were tested $20 \mathrm{~min}$ and $24 \mathrm{hr}$ after the initial odor exposure spent more time sniffing the novel odors compared to the familiar odors $(20 \mathrm{~min}, \mathrm{t}(8)=5.07, \mathrm{p}<0.05, d=3.19 ; 24 \mathrm{hr}, \mathrm{t}(8)=2.56, \mathrm{p}<$ $0.05, d=1.71$, Fig. 1), whereas those tested $48 \mathrm{hr}$ or 7 days later spent similar percentage of time sniffing both odors $(48 \mathrm{hr}, \mathrm{t}(7)=1.21, \mathrm{p}=0.270 ; 7$ days, $\mathrm{t}(6)=-0.29, \mathrm{p}=0.780$, Fig. 1$)$. These data indicate hamsters can recognize a conspecific odor $20 \mathrm{~min}$ and $24 \mathrm{hr}$, but not $48 \mathrm{hr}$ or 7 days after an initial $3 \mathrm{~min}$ exposure.

Experiment 2: Do OT and AVP increase the duration of recognition of social odors? 
Hamsters were first exposed to flank gland odor for $3 \mathrm{~min}$ and then given ICV injections of OT, AVP, or saline. Forty-eight hr later hamsters were then exposed to flank gland odor from the same individual used in the initial odor exposure and a flank gland odor from a novel hamster. Hamsters injected with saline spent similar percentage of time sniffing the novel odor and the familiar odor $(\mathrm{t}(5)=$ $0.278, p=0.792$, Fig. 2A); this is consistent with the outcomes from Experiment 1 (Fig. 2A). In contrast, hamsters that were injected with OT or AVP spent more time investigating the novel odor compared to the familiar odor (OT: $\mathrm{t}(7)=4.20, \mathrm{p}<0.05, d=3.20$; AVP: $\mathrm{t}(6)=2.64, \mathrm{p}<0.05, d=3.72$, Fig. $2 \mathrm{~A})$. Thus, OT or AVP administration after exposure to the initial odor increased the time hamsters were able to discriminate between familiar and novel odors from 24 to $48 \mathrm{hr}$. ANOVA indicated that there was a significant difference in the difference ratios among the three groups $\left(\mathrm{F}(2,18)=4.15, \mathrm{p}<0.05, \eta^{2}=0.246\right.$, Fig. 2B). Planned post hoc contrasts indicated that the difference ratios in OT and AVP injected hamsters were higher than that in saline injected hamsters (OT: $p<0.05, d=1.39$; AVP: $p<0.05, d=1.75$ ) and there was no difference of the difference ratios between the OT and AVP injected hamsters $(\mathrm{p}=0.524)$.

Experiment 3: Do selective OTR and V1aR agonists increase the duration of recognition of social odors?

The experimental protocol in the following experiment was the same as that in Experiment 2 except the drugs injected were selective OTR, V1aR agonists or saline (control). Because there was no difference between saline injected hamsters in Experiment 2 and this experiment, data from the two groups were pooled together. Again, time spent sniffing the novel odor and the familiar odor was not different in these hamsters injected with saline $(\mathrm{t}(8)=-0.39, \mathrm{p}=7.10$, Fig. 3A). In hamsters injected with the selective V1aR agonist the time spent sniffing the novel odor and the familiar odor did not was not significantly different $(\mathrm{t}(8)=-0.14, \mathrm{p}=0.895$, Fig. 3A). In contrast, hamsters injected with the OTR agonist, spent more time sniffing the novel odor than the familiar odor $(\mathrm{t}(8)=3.45, \mathrm{p}<0.05, d=2.30$, Fig.

$3 \mathrm{~A})$. There was a difference in the difference ratios among the three groups $\left(\mathrm{F}(2,24)=3.92, \mathrm{p}<0.05, \eta^{2}\right.$ 
$=0.25$, Fig. 3B). Post hoc tests indicated the hamsters injected with the OTR agonist had a significantly higher difference ratio than the hamsters injected with V1aR agonist $(\mathrm{p}<0.05, d=1.10)$ or the hamsters injected with saline $(\mathrm{p}<0.05, d=1.55)$. No significant differences were observed in difference ratios between the groups injected with the V1aR agonist and the group injected with saline $(\mathrm{p}=0.760)$.

Experiment 4: Do OTR and V1aR antagonists reduce the duration of recognition of social odors?

Hamsters were initially exposed to a flank gland odor immediately following ICV injections of OTA, V1aA, or saline. Twenty min later hamsters were then exposed to flank gland odor from the same individual used in the initial odor exposure and a flank gland odor from a novel hamster. Hamsters injected with saline spent significantly more time sniffing the novel odor than the familiar odor $(\mathrm{t}(9)=$ $3.55, \mathrm{p}<0.01, d=2.24$, Fig. 4A), consistent with data obtained in Experiment 1. Hamsters injected with the selective $\mathrm{V} 1 \mathrm{aR}$ antagonist also spent significantly more time sniffing the novel odor than the familiar odor $(\mathrm{t}(7)=3.2, \mathrm{p}<0.05, d=2.26$, Fig. 4A). In contrast, hamsters injected with the OT antagonist spent similar percentage of time investigating the familiar odor and the novel odor $(t(9)=0.49, p=0.638$, Fig.

4A). There was a significant difference in the difference ratios among the three groups $(\mathrm{F}(2,23)=4.75, \mathrm{p}$ $<0.05, \eta^{2}=0.29$, Fig. 4B). Post hoc tests revealed that the difference ratio in OT antagonist injected hamsters was lower than that in saline and V1a antagonist injected hamsters $(\mathrm{p}<0.05$ for both, $\mathrm{d}=0.94$ and 0.81 , respectively). No significant differences were observed in difference ratios between the groups injected with the V1aR antagonist and the group injected with saline $(\mathrm{p}=0.760)$.

\section{Recognition of non-social odors}

Experiment 5: How long do hamsters recognize a previously encountered non-social scent? 
Hamsters were first exposed to a lemon odor for $3 \mathrm{~min}$ and then were tested $20 \mathrm{~min}, 60 \mathrm{~min}$ or 24 hr later in an odor discrimination test with the lemon odor and an odor composed of a cocktail of lemon and vanilla together. As a control for an initial preference for the scents, another group of hamsters was not pre-exposed to the lemon odor but was directly exposed to the lemon odor and the cocktail odor. Control hamsters preferred the lemon odor over the cocktail (initial preference). To determine the retention of the recognition of the lemon odor during the pre-exposure, the percentage of time on the cocktail odor versus on the lemon odor was compared between hamsters that were pre-exposed to the lemon and hamsters that were not pre-exposed. There was a significant difference in the difference ratios among the 4 hamster groups $\left(\mathrm{F}(3,20)=3.88, \mathrm{p}<0.05, \eta^{2}=0.325\right.$, Fig. 5). Post hoc tests showed hamsters that were first exposed to lemon and then tested for the two scents with ITIs of 20min and $60 \mathrm{~min}$ had greater difference ratios than that of hamsters that were not pre-exposed to lemon $(20 \mathrm{~min}, \mathrm{p}<$ $0.05, \mathrm{~d}=1.49 ; 60 \mathrm{~min}, \mathrm{p}<0.01, \mathrm{~d}=2.24$ ). Difference ratios did not differ between hamsters that were tested with an ITI of $24 \mathrm{~h}$ and hamsters that were not pre-exposed $(\mathrm{p}=0.327)$. These data indicate hamsters can recognize non-social scents $20 \mathrm{~min}$ and $60 \mathrm{~min}$, but not $24 \mathrm{~h}$ after an initial $3 \mathrm{~min}$ encounter.

Experiment 6: Do OTR and V1aR antagonists reduce the duration of recognition of non-social odors?

Hamsters were initially exposed to lemon odor immediately following ICV injections of OTA, V1aA, or saline. Twenty minutes later hamsters were then exposed to lemon odor and the cocktail odor. Another group of hamsters was not initially exposed to lemon odor but was directly exposed to the lemon odor and the cocktail odor as an initial preference control (there was no difference in the duration of sniffing between these hamsters and those used for the same purpose in Experiment 5, so they were pooled together for data analysis). Again, to detect the recognition of the lemon odor during the preexposure, the percentage of time on the cocktail odor versus on the lemon odor (difference ratio) was compared between hamsters that were pre-exposed to the lemon and those that were not pre-exposed. 
There was a significant difference in the difference ratios among the 4 hamster groups $(F(3,34)=14.93, p$

$<0.001, \eta^{2}=0.568$, Fig. 6). All the hamsters that were initially exposed to lemon, regardless of drug administration, had greater difference ratios than hamsters that were not initially exposed to the lemon odor ( $\mathrm{p}<0.001$ for all comparisons; saline: $d=1.61$, OTA: $\mathrm{d}=3.10$, V1Aa: $d=3.26$ ). Difference ratios did not differ among the hamsters that were injected with OTA, V1aA, or saline $(\mathrm{F}(2,24)=0.77, \mathrm{p}=$ $0.475)$.

Discussion

In the present study adult male hamsters were found to recognize the social odors of other adult males for $20 \mathrm{~min}$ and $24 \mathrm{hr}$, but not $48 \mathrm{hr}$ or 7 days. The duration of this social recognition is substantially longer than that seen in many previous tests of social recognition that employed more neutral social stimuli, e.g., juvenile rats. An advantage of using a social odor as opposed to another animal as the social stimulus is that it eliminates the possibility that the properties of the stimulus will change as the result of social interactions between the stimulus animal and the test animal. As such, this social recognition test provides a simple and robust approach with a great deal of relevance and validity that can be used to investigate neurobiological mechanisms of social recognition.

The injection of either AVP or OT in the lateral ventricle prolonged recognition of flank gland odors to at least $48 \mathrm{hr}$. The OTR agonist but not the V1aR agonist mimicked these recognition enhancing effects of OT and AVP. Similarly, the OTR but not the V1aR antagonist blocked recognition of the odor. These findings indicate that both OT and AVP can significantly increase the duration of social recognition and do so by acting on OTRs and not V1aRs. Importantly, our studies also demonstrated that the effects of AVP and OT do not extend to the recognition of non-social odors. Hamsters recognized lemon scent for up to $60 \mathrm{~min}$ but not $24 \mathrm{hr}$. Unlike in the social recognition experiments, neither the OTR 
nor $\mathrm{V} 1 \mathrm{aR}$ antagonists reduced the duration of the recognition of lemon scent. These data support the hypothesis that OT and AVP enhance the recognition of social but not non-social stimuli.

The duration of recognition of the social stimulus in the present study (at least $24 \mathrm{hrs)}$ is considerably longer than the duration of recognition seen in most previous studies in rats and mice (2 3 hrs) (Dantzer, Bluthe et al. 1987, Winslow and Insel 2004, Choleris, Clipperton-Allen et al. 2009, Engelmann, Hadicke et al. 2011, Gabor, Phan et al. 2012). The recognition of social odors may be particularly important for species like Syrian hamsters because individuals do not encounter other individuals frequently in the wild (Gattermann, Johnston et al. 2008). The longer duration of social recognition may also result from using flank gland odors as the social cue because these odors represent a powerful social stimulus that serves to communicate important social information such as dominance status (Ferris, Axelson et al. 1987, Ferris, Melloni et al. 2013). The recognition and memory of social stimuli can be quite sophisticated in rodents. Social recognition can be influenced by social and environmental context including the sex of the stimulus animal, the place where the initial exposure occurs (home cage, clean cage, or cage of another individual) (Zheng, Foley et al. 2013), and whether the stimulus animal was infected with parasites (Kavaliers, Choleris et al. 2005). Rodents are also capable of kin recognition and the true recognition of specific individuals (e.g. Mateo and Johnston 2003, Johnston and Peng 2008, Petrulis 2009). It will be important to determine if OT and AVP may be involved in mediating some of the more complex forms of social recognition.

A considerable body of evidence has shown that OT and AVP can act either peripherally or centrally to influence social recognition in rats and mice (Dantzer, Bluthe et al. 1987, Engelmann and Landgraf 1994, Ferguson, Aldag et al. 2001, Winslow and Insel 2004, Larrazolo-López, Kendrick et al. 2008, Lukas, Bredewold et al. 2011, Albers 2012, Gabor, Phan et al. 2012). Peripheral AVP administration increases social recognition of juveniles in mice as well as in rats (Dantzer, Bluthe et al. 1987, Bluthe, Gheusi et al. 1993) and peripheral administration of low doses of OT facilitates social recognition of juvenile rats in a dose-dependent manner (Popik, Vetulani et al. 1992). In the CNS, OT 
and AVP can act in multiple brain sites to influence social recognition. Medial amygdala (MeA) has been reported as an essential site for OT's effects on social recognition. Antagonism of OTRs in the MeA impairs social recognition of juveniles and OT injection into the MeA rescues the deficits in social recognition seen in OT knock-out mice (Ferguson, Young et al. 2000, Ferguson, Aldag et al. 2001). Endogenous OT release in the main olfactory bulb (MOB) can enhance the retention of social memory in rats and this enhancement can be blocked by an OTR antagonist (Larrazolo-Lopez, Kendrick et al. 2008). AVP appears to influence social recognition by acting on the lateral septum (LS) and the MOB.

Administration of AVP in the LS extends the recognition of juvenile rats and antagonism of V1aRs in this area impairs the recognition (Dantzer, Koob et al. 1988, Veenema, Bredewold et al. 2012). AVP injected into the LS restores social recognition in AVP-deficit of Brattleboro rats (Engelmann and Landgraf 1994). AVP injection in the MOB also prolongs the recognition of juvenile rats (Dluzen, Muraoka et al. 1998) and V1aR antagonism in the MOB impairs recognition (Tobin, Hashimoto et al. 2010). Taken together, these studies show there are multiple regions in the CNS where OT and AVP can influence social recognition.

Indeed, there are several studies that suggest that V1a receptors are important for social recognition in rats. Infusions of antisense V1a oligonucleotides into the LS impair social recognition (Landgraf, Gerstberger et al. 1995) and over-expression of V1aRs in the LS by viral vectors enhances recognition in rats (Landgraf, Frank et al. 2003). Other studies have investigated the role of OTRs and V1aRs in social recognition using knock-out mice (Bielsky, Hu et al. 2004, Choleris, Little et al. 2007). Severe impairments in social recognition are found in OTR knock-out and knock-down mice (Choleris, Little et al. 2007, Macbeth, Lee et al. 2009). Conflicting results, however, have been reported in studies employing the same strains of V1aR knock-out mice. One group found that V1aR knock-out mice did not habituate to the presence of ovariectomized females, suggesting an impairment in social recognition (Bielsky, Hu et al. 2004, Bielsky, Hu et al. 2005). In contrast, another study using V1aR knock-out mice from the same source in a similar habituation and dishabituation paradigm found a subtle olfactory deficit 
but normal social recognition (Wersinger, Caldwell et al. 2007). Our data are consistent with the later study suggesting that OTRs and not V1aRs mediate social recognition. The reasons for the discrepancy in studies regarding V1aRs are unknown. It is possible that the V1aR is involved in other behaviors such as anxiety-related behavior that may indirectly affect social recognition in a less profound way. It could be that different testing models such as using a juvenile animal versus social odors may underlie these different results. It is also possible, of course, that the role of V1aRs in social recognition may vary across species.

The site(s) where OT and/or AVP act to facilitate social recognition in Syrian hamsters are not known. There is considerable information about the distribution of AVP and V1a receptors in Syrian hamsters (for a review see Albers, 2015), but considerably less is known about the anatomical location of OT and its receptors. AVP immunoreactivity is found extensively throughout the brain in many of the same structures as seen in other rodent species (e.g., for example, the supraoptic, paraventricular and suprachiasmatic nuclei). Interestingly, however in Syrian hamsters there is a nearly complete lack of AVP containing cell bodies in the extended amygdala as well as an absence of AVP fibers in the LS (Dubois-Dauphin, Pevet et al. 1990, Albers, Rowland et al. 1991, Ferris, Delville et al. 1995). In contrast, in addition to the presence of OT containing cells bodies in the several hypothalamic nuclei in Syrian hamsters, OT immunoreactive cell bodies and fibers are also found throughout the extended amygdala (Whitman and Albers 1998). OT receptor binding sites are also found in a variety of brain regions in Syrian hamsters such as in the extended amygdala and the lateral septum (DuboisDauphin, Pevet et al. 1992). It will be interesting to determine whether OT receptors found within the extended amygdala and/or LS play a critical role in regulating social recognitions in hamsters.

The present study provides the first evidence that OT and AVP act on OTRs and not V1aRs to produce behavioral effects. Recently, another study from our lab found that both OT and AVP induce social communication via acting on V1aRs and not OTRs in hamsters (Song, McCann et al. 2014). Other studies have also found that both OT and AVP can act on V1a receptors to influence behavioral and 
physiological responses (Schorscher-Petcu, Sotocinal et al. 2010, Sala, Braida et al. 2011, Ramos, Hicks et al. 2013, Qiu, Qiu et al. 2014, Albers 2015). Taken together, these data suggest that while OT and AVP can activate both OTRs and V1aRs to influence social behavior OTRs regulate some social behaviors and $\mathrm{V} 1 \mathrm{aRs}$ regulate other social behaviors. At present there is little evidence that a combination of OTR and V1aR activation is involved in regulating the same behavior (cf. Liu, Curtis et al. 2001), in contrast, the existing data seem to suggest that each behavior is regulated by either OTRs or V1aRs. It is interesting to note that while both OTRs and V1aRs are found in limbic structures such as the extended amygdala they rarely overlap (Veinante and Freund-Mercier 1997). As such, the activation of small anatomically separable populations of OTRs or V1aRs by the local synaptic release of neuropeptide may influence a single social behavior while the release of large amounts of AVP and/or OT by volume transmission could potentially activate large numbers of both OTRs and V1aRs and thereby influence the expression of multiple behaviors.

Conclusion

The present study employed a new test of social recognition of adult conspecifics wherein flank gland odors of adult male hamsters were used as the social cue to investigate neurobiological mechanisms underlying social recognition. Centrally administered OT and AVP significantly prolong the recognition of social cues from other adult individuals but these enhancing effects of OT and AVP do not extend to recognition of non-social cues. Further, both OT and AVP were found to act on OTRs but not V1aRs to influence social recognition, thus providing the first evidence that AVP and OT can act on OTRs to regulate social behavior. These findings emphasize the potential significance of the interactions between OT, AVP and their receptors in regulating complex social behavior in the central nervous system.

\section{Acknowledgements}


We would like to thank Dr. Maurice Manning for his generous gifts of the OT and AVP receptor agonists and antagonists used in this study. This work was supported by NSF IOS-0923301 to HEA. 
The authors declare no conflicts of interest. 


\section{Contributors:}

Song designed and participated in conducting all experiments, analyzed the data, and also wrote the first draft of this manuscript. Larkin participated in conducting the experiments, scored the videos, and contributed to the editing of the manuscript. O'Malley participated in conducting the experiments and scored the videos. Dr. Albers supervised all the experiments, data analyses, and also contributed significantly in the preparation and editing of the manuscript. 
Figure Captions

Figure 1. Hamsters spent more time in sniffing a novel odor versus a familiar odor that they encountered 20min and $24 \mathrm{hr}$ earlier. But they spent similar percentage of time on both odors when they encountered the 'familiar odor' $48 \mathrm{hr}$ or 7 days earlier. * indicates a significant difference between Familiar and Novel.

Figure 2. A. Hamsters injected with OT or AVP spent less time in sniffing a familiar odor 48hr after their initial exposure, whereas control hamsters spent the same percentage of time on the familiar and novel odors. B. Hamsters injected with OT or AVP had greater percentages of extra time over the novel odor (difference ratios) than saline control hamsters. * indicates a significant difference between Familiar and Novel. \# indicates a significant difference compared with saline.

Figure 3. A. Hamsters injected with OTR Ag spent less time with the familiar odor 48hr after their initial exposure, whereas control hamsters as well as hamsters injected with V1aR Ag spent the same percentage of time with both the familiar and novel odors. B. OTR Ag hamsters had a greater percentage of extra time over the novel odor (difference ratio) than saline and V1aR Ag hamsters. * indicates a significant difference between Familiar and Novel. \# indicates a significant difference compared with saline. Ag: agonist

Figure 4. A. Hamsters injected with saline and V1aA spent more time with a novel odor versus a familiar odor they encountered 20min earlier; hamsters injected with OTA spent similar percentage of time on both odors. B. Hamsters injected with OTA had a smaller percentage of extra time (difference ratio) than hamsters injected with saline or V1aA. OTA: OTR antagonist; V1Aa: V1aR antagonist. * indicates a 
significant difference between Familiar and Novel. \# indicates a significant difference compared with saline.

Figure 5. A. Hamsters that were not pre-exposed to lemon (the Initial group) spent more time with lemon when presented with a lemon and vanilla cocktail, whereas hamsters that were pre-exposed to lemon did not. B. Hamsters that were pre-exposed $20 \mathrm{~min}$ and $60 \mathrm{~min}$ earlier had significantly greater difference ratios than hamsters in the Initial group. Hamsters that were pre-exposed $24 \mathrm{~h}$ earlier had similar difference ratios than the Initial group. * indicates a significant difference between Lemon and Cocktail. \# indicates a significant difference compared with Initial.

Figure 6. A. Hamsters that were not pre-exposed (Initial group) spent more time with lemon; whereas hamsters that were injected Sal, OTA, or V1aA did not. B. Hamsters that were injected with Saline, OTA, or V1aA had greater difference ratios than hamsters in the Initial group. OTA: OTR antagonist; V1Aa: V1aR antagonist. * indicates a significant difference between Lemon and Cocktail. \# indicates a significant difference compared with Initial. 


\section{Reference}

Albers, H. E. (2012). "The regulation of social recognition, social communication and aggression: vasopressin in the social behavior neural network." Hormones and behavior 61(3): 283-292. Albers, H. E. (2015). "Species, sex and individual differences in the vasotocin/vasopressin system: relationship to neurochemical signaling in the social behavior neural network." Front Neuroendocrinol 36: 49-71.

Albers, H. E., J. Pollock, W. H. Simmons and C. F. Ferris (1986). "A V1-like receptor mediates vasopressin-induced flank marking behavior in hamster hypothalamus." ¿ Neurosci 6(7): 20852089.

Albers, H. E., C. M. Rowland and C. F. Ferris (1991). "Arginine-vasopressin immunoreactivity is not altered by photoperiod or gonadal hormones in the Syrian hamster (Mesocricetus auratus)." Brain Res 539(1): 137-142.

Bielsky, I. F., S. B. Hu, X. Ren, E. F. Terwilliger and L. J. Young (2005). "The V1a vasopressin receptor is necessary and sufficient for normal social recognition: a gene replacement study." Neuron 47(4): 503-513.

Bielsky, I. F., S. B. Hu, K. L. Szegda, H. Westphal and L. J. Young (2004). "Profound impairment in social recognition and reduction in anxiety-like behavior in vasopressin V1a receptor knockout mice." Neuropsychopharmacology 29(3): 483-493.

Bluthe, R. M., G. Gheusi and R. Dantzer (1993). "Gonadal steroids influence the involvement of arginine vasopressin in social recognition in mice." Psychoneuroendocrinology 18(4): 323-335. Caldwell, H. K. and H. E. Albers (2015). "Oxytocin, Vasopressin, and the Motivational Forces that Drive Social Behaviors." Curr Top Behav Neurosci.

Choleris, E., A. E. Clipperton-Allen, A. Phan and M. Kavaliers (2009). "Neuroendocrinology of social information processing in rats and mice." Frontiers in neuroendocrinology 30(4): 442-459. 
Choleris, E., S. R. Little, J. A. Mong, S. V. Puram, R. Langer and D. W. Pfaff (2007). "Microparticlebased delivery of oxytocin receptor antisense DNA in the medial amygdala blocks social recognition in female mice." Proceedings of the National Academy of Sciences of the United States of America 104(11): 4670-4675.

Dantzer, R., R. M. Bluthe, G. F. Koob and M. Le Moal (1987). "Modulation of social memory in male rats by neurohypophyseal peptides." Psychopharmacology (Berl) 91(3): 363-368.

Dantzer, R., G. F. Koob, R. M. Bluthe and M. Le Moal (1988). "Septal vasopressin modulates social memory in male rats." Brain Res 457(1): 143-147.

Dluzen, D. E., S. Muraoka, M. Engelmann and R. Landgraf (1998). "The effects of infusion of arginine vasopressin, oxytocin, or their antagonists into the olfactory bulb upon social recognition responses in male rats." Peptides 19(6): 999-1005.

Dubois-Dauphin, M., P. Pevet, C. Barberis, E. Tribollet and J. J. Dreifuss (1992). "Localization of binding sites for oxytocin in the brain of the golden hamster." Neuroreport 3(9): 797-800.

Dubois-Dauphin, M., P. Pevet, E. Tribollet and J. J. Dreifuss (1990). "Vasopressin in the brain of the golden hamster: the distribution of vasopressin binding sites and of immunoreactivity to the vasopressin-related glycopeptide." L Comp Neurol 300(4): 535-548.

Engelmann, M., J. Hadicke and J. Noack (2011). "Testing declarative memory in laboratory rats and mice using the nonconditioned social discrimination procedure." Nat. Protocols 6(8): 1152-1162. Engelmann, M. and R. Landgraf (1994). "Microdialysis administration of vasopressin into the septum improves social recognition in Brattleboro rats." Physiol Behav 55(1): 145-149.

Ferguson, J. N., J. M. Aldag, T. R. Insel and L. J. Young (2001). "Oxytocin in the Medial Amygdala is Essential for Social Recognition in the Mouse." The Journal of neuroscience : the official journal of the Society for Neuroscience 21(20): 8278-8285.

Ferguson, J. N., L. J. Young, E. F. Hearn, M. M. Matzuk, T. R. Insel and J. T. Winslow (2000). "Social amnesia in mice lacking the oxytocin gene." Nat Genet 25(3): 284-288. 
Ferris, C. F., H. E. Albers, S. M. Wesolowski, B. D. Goldman and S. E. Luman (1984). "Vasopressin injected into the hypothalamus triggers a stereotypic behavior in golden hamsters." Science 224(4648): 521-523.

Ferris, C. F., J. F. Axelson, L. H. Shinto and H. E. Albers (1987). "Scent marking and the maintenance of dominant/subordinate status in male golden hamsters." Physiol Behav 40(5): 661-664.

Ferris, C. F., Y. Delville, M. A. Miller, D. M. Dorsa and G. J. De Vries (1995). "Distribution of small vasopressinergic neurons in golden hamsters." L Comp Neurol 360(4): 589-598.

Ferris, C. F., R. H. Melloni and H. E. Albers (2013). "Role of vasopressin in flank marking and aggression." Oxytocin, Vasopressin, and Related Peptides in the Regulation of Behavior, ed. E. Choleris, D. W. Pfaff, and M. Kavaliers. Published by Cambridge University Press. (C) Cambridge University Press 2013.

Ferris, C. F., E. A. Singer, D. M. Meenan and H. Elliott Albers (1988). "Inhibition of vasopressinstimulated flank marking behavior by V1-receptor antagonists." European Journal of Pharmacology 154(2): 153-159.

Gabor, C. S., A. Phan, A. E. Clipperton-Allen, M. Kavaliers and E. Choleris (2012). "Interplay of oxytocin, vasopressin, and sex hormones in the regulation of social recognition." Behav Neurosci 126(1): 97-109.

Gattermann, R., R. E. Johnston, N. Yigit, P. Fritzsche, S. Larimer, S. Ozkurt, K. Neumann, Z. Song, E. Colak, J. Johnston and M. E. McPhee (2008). "Golden hamsters are nocturnal in captivity but diurnal in nature." Biol Lett 4(3): 253-255.

Gimpl, G. and F. Fahrenholz (2001). "The Oxytocin Receptor System: Structure, Function, and Regulation." Physiological reviews 81(2): 629-683.

Halpin, Z. T. (1976). "The role of individual recognition by odors in the social interactions of the Mongolian gerbil (Meriones unguiculatus)." Behaviour 58(1-2): 117-130. 
Johnston, R. E. (1993). "Memory for individual scent in hamsters (Mesocricetus auratus) as assessed by habituation methods." I Comp Psychol 107(2): 201-207.

Johnston, R. E. and T. A. Bullock (2001). "Individual recognition by use of odours in golden hamsters: the nature of individual representations." Animal Behaviour 61(3): 545-557.

Johnston, R. E. and N. A. Lee (1976). "Persistence of the odor deposited by two functionally distinct scent marking behaviors of golden hamsters." Behavioral Biology 16(2): 199-210.

Johnston, R. E. and A. Peng (2008). "Memory for individuals: hamsters (Mesocricetus auratus) require contact to develop multicomponent representations (concepts) of others." \Comp Psychol 122(2): 121-131.

Kavaliers, M., E. Choleris and D. W. Pfaff (2005). "Genes, odours and the recognition of parasitized individuals by rodents." Trends Parasitol 21(9): 423-429.

Landgraf, R., E. Frank, J. M. Aldag, I. D. Neumann, C. A. Sharer, X. Ren, E. F. Terwilliger, M. Niwa, A. Wigger and L. J. Young (2003). "Viral vector-mediated gene transfer of the vole V1a vasopressin receptor in the rat septum: improved social discrimination and active social behaviour." Eur I Neurosci 18(2): 403-411.

Landgraf, R., R. Gerstberger, A. Montkowski, J. C. Probst, C. T. Wotjak, F. Holsboer and M. Engelmann (1995). "V1 vasopressin receptor antisense oligodeoxynucleotide into septum reduces vasopressin binding, social discrimination abilities, and anxiety-related behavior in rats." INeurosci 15(6): 4250-4258.

Larrazolo-Lopez, A., K. M. Kendrick, M. Aburto-Arciniega, V. Arriaga-Avila, S. Morimoto, M. Frias and R. Guevara-Guzman (2008). "Vaginocervical stimulation enhances social recognition memory in rats via oxytocin release in the olfactory bulb." Neuroscience 152(3): 585-593.

Larrazolo-López, A., K. M. Kendrick, M. Aburto-Arciniega, V. Arriaga-Ávila, S. Morimoto, M. Frias and R. Guevara-Guzmán (2008). "Vaginocervical stimulation enhances social recognition memory in rats via oxytocin release in the olfactory bulb." Neuroscience 152(3): 585-593. 
Le Moal, M., R. Dantzer, B. Michaud and G. F. Koob (1987). "Centrally injected arginine vasopressin (AVP) facilitates social memory in rats." Neuroscience Letters 77(3): 353-359.

Liu, Y., J. T. Curtis and Z. Wang (2001). "Vasopressin in the lateral septum regulates pair bond formation in male prairie voles (Microtus ochrogaster)." Behavioral neuroscience 115(4): 910-919. Lukas, M., R. Bredewold, R. Landgraf, I. D. Neumann and A. H. Veenema (2011). "Early life stress impairs social recognition due to a blunted response of vasopressin release within the septum of adult male rats." Psychoneuroendocrinology 36(6): 843-853.

Macbeth, A. H., H. J. Lee, J. Edds and W. S. Young, 3rd (2009). "Oxytocin and the oxytocin receptor underlie intrastrain, but not interstrain, social recognition." Genes Brain Behav 8(5): 558-567. Manning, M., A. Misicka, A. Olma, K. Bankowski, S. Stoev, B. Chini, T. Durroux, B. Mouillac, M. Corbani and G. Guillon (2012). "Oxytocin and vasopressin agonists and antagonists as research tools and potential therapeutics." L Neuroendocrinol 24(4): 609-628.

Mateo, J. M. and R. E. Johnston (2003). "Kin recognition by self-referent phenotype matching: weighing the evidence." Anim Cogn 6(1): 73-76.

Maybauer, M. O., D. M. Maybauer, P. Enkhbaatar and D. L. Traber (2008). "Physiology of the vasopressin receptors." Best Pract Res Clin Anaesthesiol 22(2): 253-263.

Nephew, B. C. and R. S. Bridges (2008). "Central actions of arginine vasopressin and a V1a receptor antagonist on maternal aggression, maternal behavior, and grooming in lactating rats."

Pharmacology, biochemistry, and behavior 91(1): 77-83.

Petrulis, A. (2009). "Neural mechanisms of individual and sexual recognition in Syrian hamsters (Mesocricetus auratus)." Behav Brain Res 200(2): 260-267.

Popik, P., J. Vetulani and J. M. van Ree (1992). "Low doses of oxytocin facilitate social recognition in rats." Psychopharmacology (Berl) 106(1): 71-74. 
Qiu, F., C. Y. Qiu, H. Cai, T. T. Liu, Z. W. Qu, Z. Yang, J. D. Li, Q. Y. Zhou and W. P. Hu (2014). "Oxytocin inhibits the activity of acid-sensing ion channels through the vasopressin, V1A receptor in primary sensory neurons." Br J Pharmacol 171(12): 3065-3076.

Ramos, L., C. Hicks, R. Kevin, A. Caminer, R. Narlawar, M. Kassiou and I. S. McGregor (2013). "Acute prosocial effects of oxytocin and vasopressin when given alone or in combination with 3,4methylenedioxymethamphetamine in rats: involvement of the V1A receptor." Neuropsychopharmacology 38(11): 2249-2259.

Sala, M., D. Braida, D. Lentini, M. Busnelli, E. Bulgheroni, V. Capurro, A. Finardi, A. Donzelli, L. Pattini, T. Rubino, D. Parolaro, K. Nishimori, M. Parenti and B. Chini (2011). "Pharmacologic Rescue of Impaired Cognitive Flexibility, Social Deficits, Increased Aggression, and Seizure Susceptibility in Oxytocin Receptor Null Mice: A Neurobehavioral Model of Autism." Biological Psychiatry 69(9): 875-882.

Schorscher-Petcu, A., S. Sotocinal, S. Ciura, A. Dupre, J. Ritchie, R. E. Sorge, J. N. Crawley, S. B. Hu, K. Nishimori, L. J. Young, E. Tribollet, R. Quirion and J. S. Mogil (2010). "Oxytocin-induced analgesia and scratching are mediated by the vasopressin-1A receptor in the mouse." LNeurosci 30(24): 8274-8284.

Song, Z., K. E. McCann, J. K. t. McNeill, T. E. Larkin, 2nd, K. L. Huhman and H. E. Albers (2014). "Oxytocin induces social communication by activating arginine-vasopressin V1a receptors and not oxytocin receptors." Psychoneuroendocrinology 50c: 14-19.

Tobin, V. A., H. Hashimoto, D. W. Wacker, Y. Takayanagi, K. Langnaese, C. Caquineau, J. Noack, R. Landgraf, T. Onaka, G. Leng, S. L. Meddle, M. Engelmann and M. Ludwig (2010). "An intrinsic vasopressin system in the olfactory bulb is involved in social recognition." Nature 464(7287): 413417.

Veenema, A. H., R. Bredewold and G. J. De Vries (2012). "Vasopressin regulates social recognition in juvenile and adult rats of both sexes, but in sex- and age-specific ways." Horm Behav 61(1): 50-56. 
Veinante, P. and M. J. Freund-Mercier (1997). "Distribution of oxytocin- and vasopressin-binding sites in the rat extended amygdala: a histoautoradiographic study." L Comp Neurol 383(3): 305-325.

Wersinger, S. R., H. K. Caldwell, L. Martinez, P. Gold, S. B. Hu and W. S. Young, 3rd (2007).

"Vasopressin 1a receptor knockout mice have a subtle olfactory deficit but normal aggression." Genes Brain Behav 6(6): 540-551.

Whitman, D. C. and H. E. Albers (1998). "Oxytocin immunoreactivity in the hypothalamus of female hamsters." Cell Tissue Res 291(2): 231-237.

Winslow, J. T. and T. R. Insel (2004). "Neuroendocrine basis of social recognition." Current opinion in neurobiology 14(2): 248-253.

Zheng, D. J., L. Foley, A. Rehman and A. G. Ophir (2013). "Social recognition is context dependent in single male prairie voles." Anim Behav $\mathbf{8 6}(5)$. 


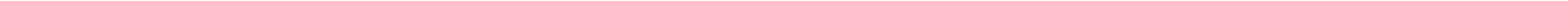




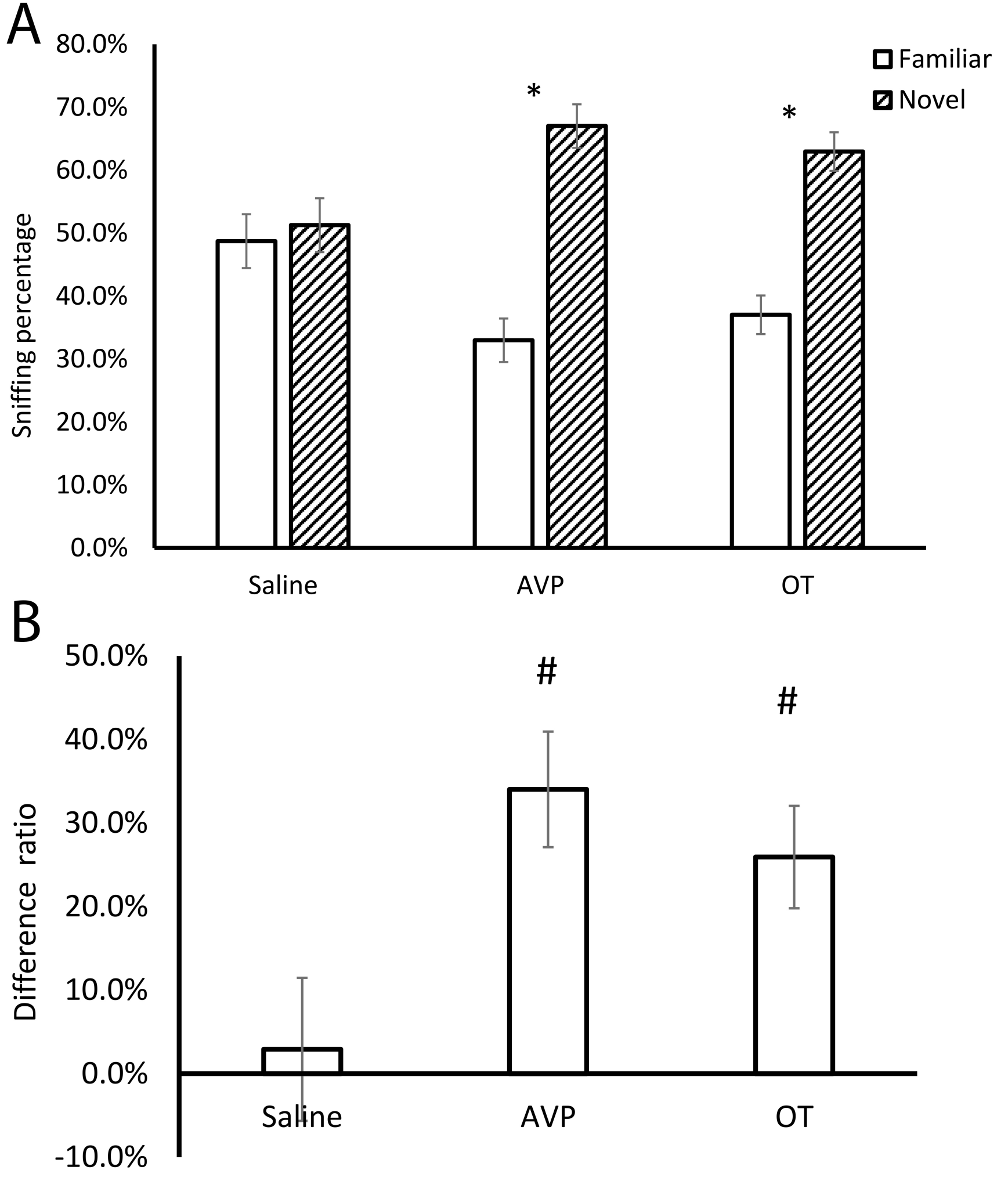




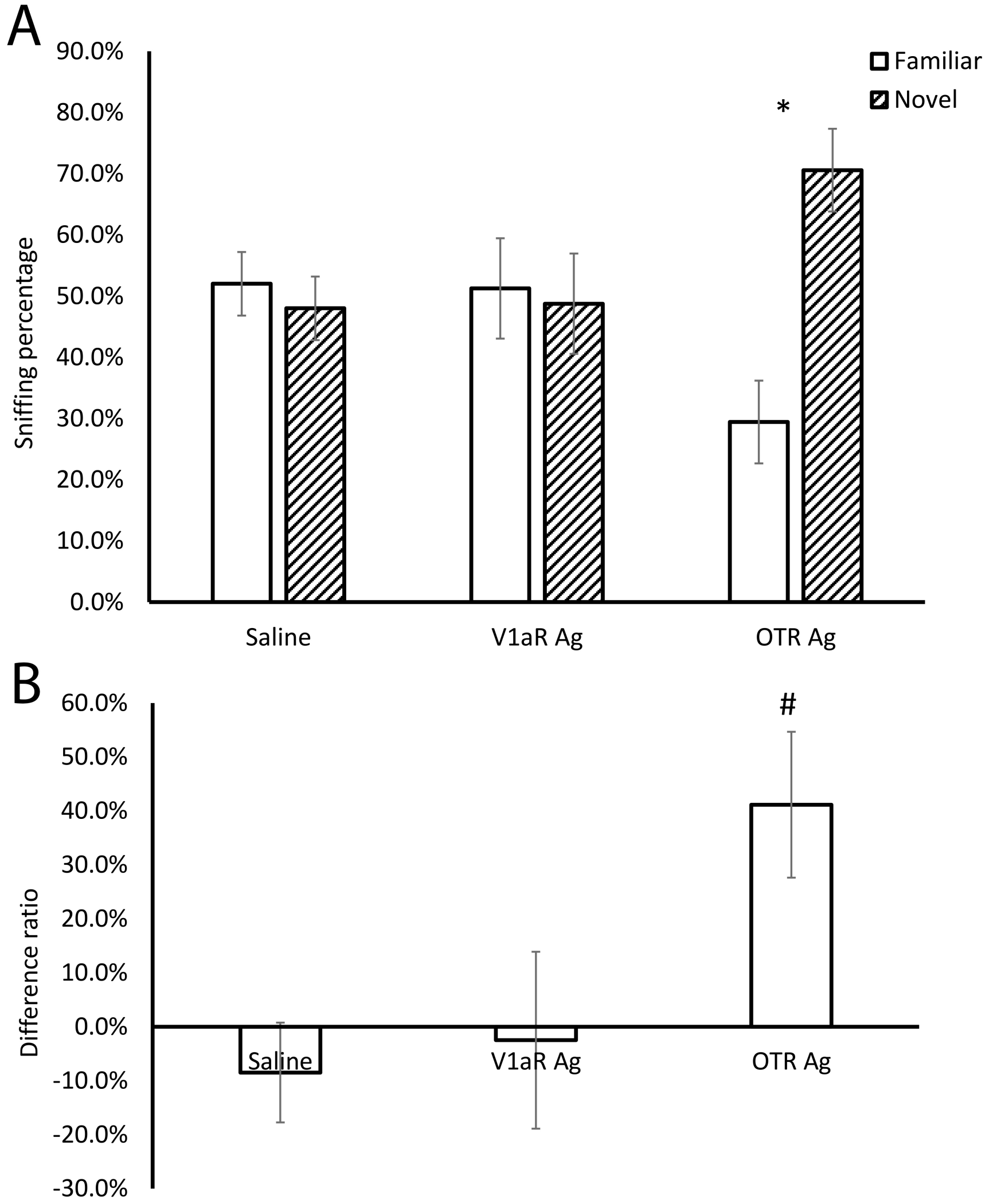




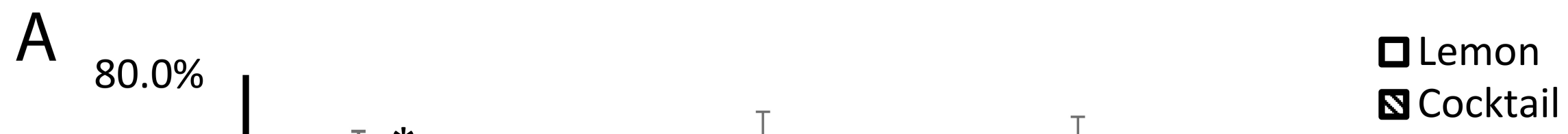

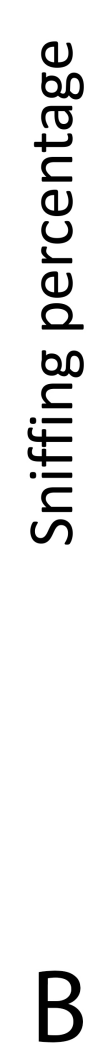

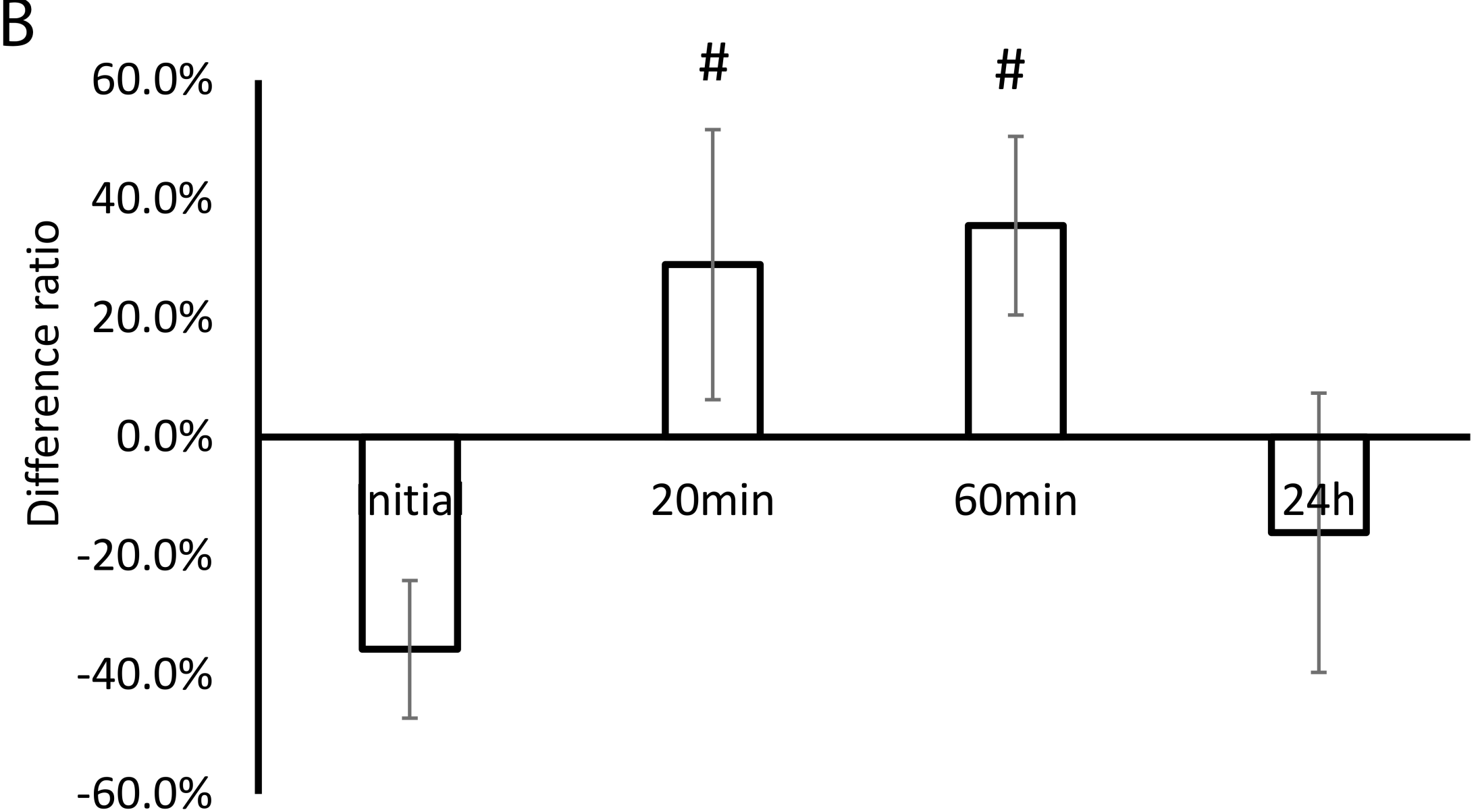


A

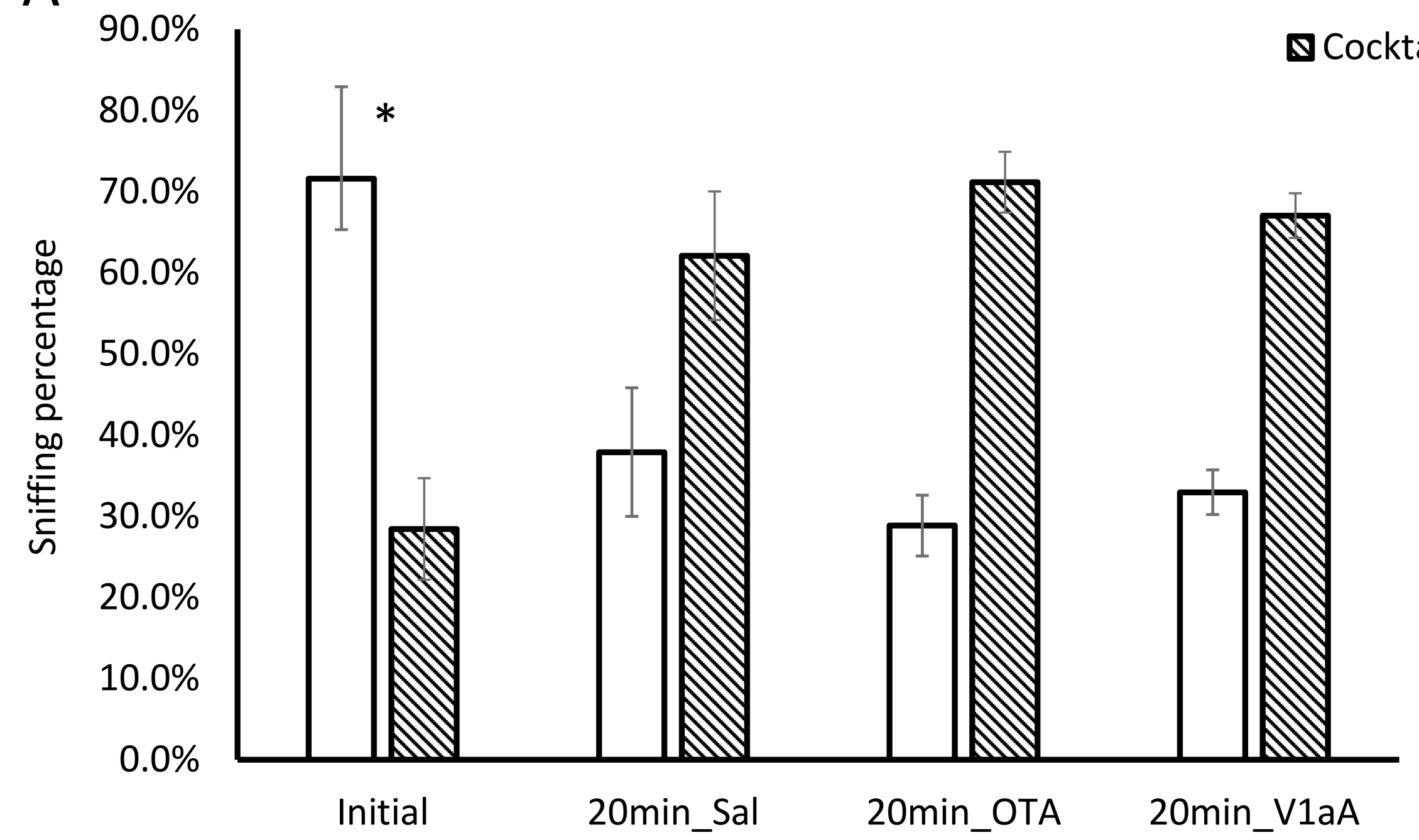

B

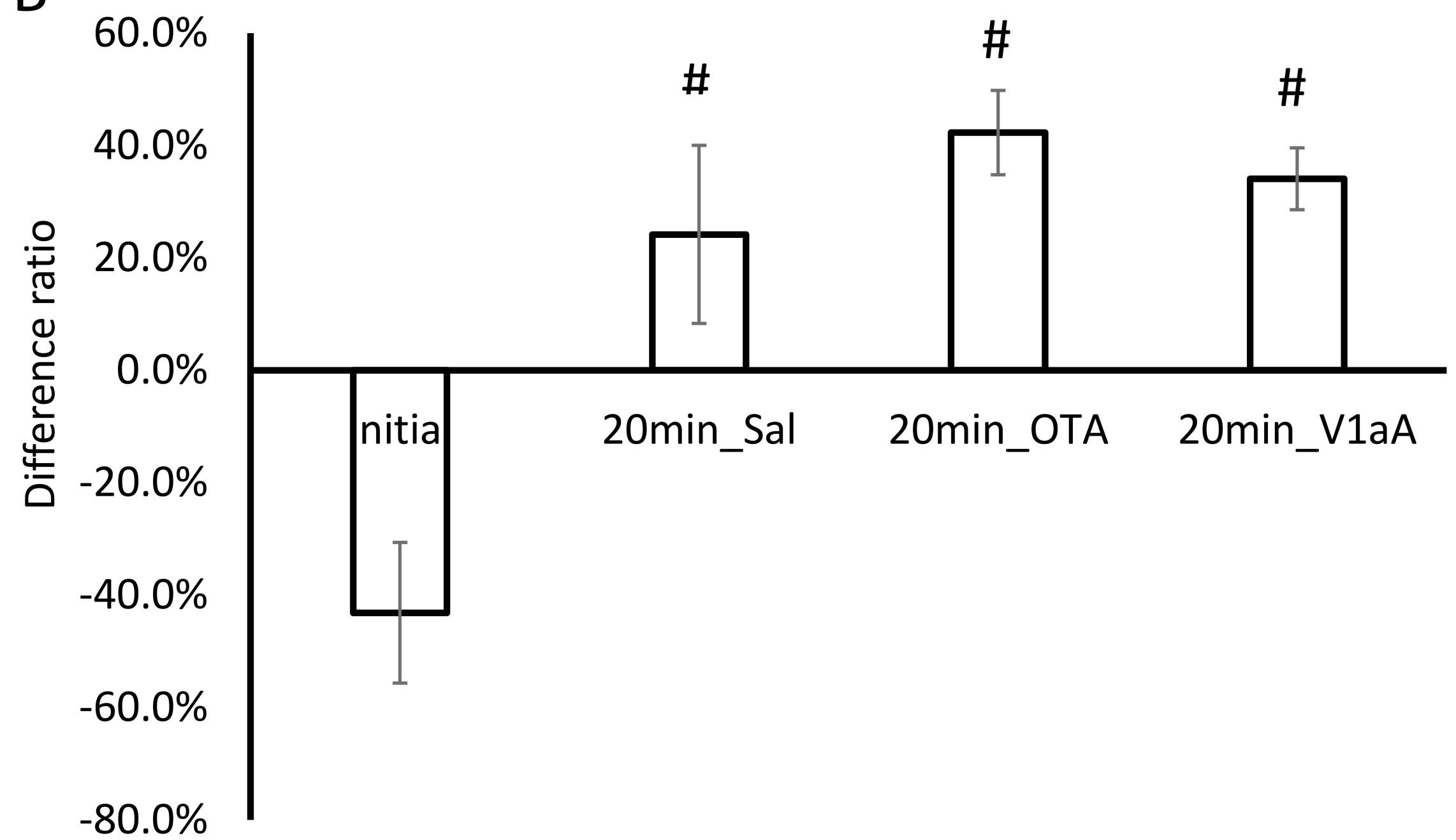

